\title{
Experimental investigation of methane adsorption and desorption in water-bearing shale
}

\author{
Aifen $\mathrm{Li}^{1,2}$, Wencheng $\operatorname{Han}^{1,2 \odot *}$, Qi Fang ${ }^{1,2}$, Asadullah Memon ${ }^{1,2}$, Min Ma ${ }^{1,2}$ \\ ${ }^{1}$ School of petroleum engineering, China University of Petroleum (East China), Qingdao 266580, P. R. China \\ ${ }^{2}$ Research Center of Multiphase Flow in Porous Media, China University of Petroleum (East China), Qingdao 266580, P. R. China
}

\section{Keywords:}

Water-bearing shale

methane

water content

adsorption

desorption

Cited as:

Li, A., Han, W., Fang, Q., Memon, A., $\mathrm{Ma}, \mathrm{M}$. Experimental investigation of methane adsorption and desorption in water-bearing shale. Capillarity, 2020, 3(3): 45-55,

doi: 10.46690/capi.2020.03.02.

\begin{abstract}
:
Methane adsorption and desorption in shale can significantly be affected by water due to the water-bearing depositional environment of shale and the application of hydraulic fracturing technology in shale gas production. The characteristics of shale gas adsorption and desorption are comprehensively affected by the temperature, pressure, and especially, the water content in the reservoir. To further explore the impact of water on shale gas adsorption and desorption, the adsorption-desorption experiments of methane in waterbearing shale at different temperatures and different pressures are performed. Afterward, the adsorption behavior and desorption hysteresis are characterized by employing the Langmuir model and Langmuir $+\lambda$ model. Finally, the ways of the pressure, temperature, and water combinedly affect shale gas adsorption behavior and desorption hysteresis are analyzed. The results show that adsorption and desorption of methane in the water-bearing shale are irreversible, which are consistent with the Langmuir model and the Langmuir $+\lambda$ model, respectively. An increase in temperature will reduce adsorption and promote desorption, as an increase in temperature essentially enhances the thermal movement of methane molecules. Water lowers the adsorption and desorption of methane in shale, as the water molecules occupy the adsorption sites in organic pores and clay mineral pores in different ways. However, the effect of temperature and water content on adsorption is closely related to the pressure. The lower the pressure, the more significant the effect of temperature and water content. The combined effect analysis demonstrates that the impact of water on methane adsorption in shale is much more significant than that of the temperature. Still, desorption is simultaneously affected by both temperature and water content. As the pressure decreases in the desorption process, the desorption rate is dominantly affected by water when the pressure is lower than $8 \mathrm{MPa}$, and the desorption rate is aggressively affected by temperature when the pressure is at above $8 \mathrm{MPa}$.
\end{abstract}

\section{Introduction}

With the increasing consumption of oil and gas resources globally, unconventional reservoir has gradually become a significant energy supplement to decrease the gap between the growing energy demand and the shortage of traditional energy resources (Cai et al., 2019). Shale gas is widely suggested as a promising resource because of its clean energy and large reserves (Jarvie et al., 2007; Mcglade et al., 2013). In shale gas reservoirs, gas is stored in free gas, adsorbed gas, and dissolved gas (Jarvie et al., 2007; Mcglade et al., 2013; Sandoval et al., 2017). It is commonly considered that the adsorbed gas in the shale reservoir accounts for 20\%-85\% of the total gas content (Hill and Nelson, 2000). Therefore, understanding the characteristics of adsorption and desorption of shale gas is the key to correctly evaluate the gas content and effectively enhance gas production.

The adsorption and desorption of shale gas in the reservoir are complicatedly affected by the intrinsic properties of shale such as the total organic carbon (TOC), mineral composition, thermal maturity, pore structures, and external conditions such as temperature, pressure, and water content. The effect of TOC content, thermal maturity, clay content, and temperature on the adsorption capacity of shale have been reported in various literature. It is generally accepted that the higher TOC and clay content results in a higher adsorption capacity since the adsorption sites for gas are predominantly provided by the organic matter and clay minerals in shale (Yuan et al., 2014; Wang et al., 2015, 2016; Xiong et al., 2017; Jiao et al., 2019; Zhang et al., 2019). A positive correlation of methane

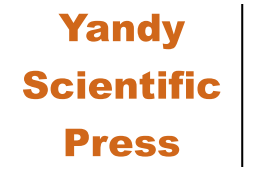

* Corresponding author.

E-mail address: aifenli123@163.com (A. Li); hwencheng57@126.com (W. Han); fang1302010223@gmail.com (Q. Fang);

1b1702015@s.upc.edu.cn (A. Memom); b17020094@s.upc.edu.cn (M. Ma).

2652-3310 (C) The Author(s) 2020.

Received September 3, 2020; revised September 10, 2020; accepted September 10, 2020; available online September 13 , 2020. 
adsorption capacity with shale thermal maturity was also observed from experimental studies (Lu et al., 1995; Chalmers and Bustin, 2007a, 2007b; Zhang et al., 2012; Rexer et al., 2014; Huang et al., 2018a). The vitrinite random reflectance in Posidonia shales increased by $0.6 \%$, leading to a $36 \%$ increase in methane adsorption (Rexer et al., 2014). Molecular simulation studies addressed that the pore size is another vital factor in gas sorption in shale reservoir. Methane adsorption in micropores is mainly controlled by the potential superimposed effect of pore wall, and the adsorption capacity increases significantly by the increasing in pore size. In contrast, the adsorption in mesopore is dominated by the surface potential effect and the adsorption capacity is negatively correlated with the pore size (Xiong et al., 2017). Adsorption of gas in shale is essentially an exothermic process that the higher temperatures generally result in a decrease in adsorption capacity (Fan et al., 2014; Zhao et al., 2018).

Numerous investigations on shale gas adsorption have been performed, but dry samples are commonly used in the aforementioned studies. Water is omnipresent in shale reservoirs (Ahmad ang Haghighi, 2013; Liu and Wang, 2013; Fang et al., 2014; Li et al., 2016; Al-Mutarreb et al., 2018; Yang et al., 2020). The process from shale deposition to methane production is carried out in a water-bearing environment (Herrle et al., 2003; Al-Mutarreb et al., 2018). Moreover, wide applications of hydraulic fracturing in shale gas production show that more than half of the fracturing fluid remains in the reservoirs (Wattenbarger and Alkouh, 2013; Ghanbari and Dehghanpour, 2016; Zeng et al., 2020), leading to a significant impact on methane adsorption and desorption. The significance of water on shale gas adsorption has drawn great attention in recent years. It is generally believed that water reduces the shale gas adsorption evidently (Ross and Bustin, 2007; Gasparik et al., 2012; Tan et al., 2014; Yuan et al., 2014; Merkel et al., 2015). Researchers found that water affects methane adsorption in three stages, which are related to the intrinsic properties of the shale (Yang et al., 2016; Fan et al., 2018). Similarly to the moist coal adsorption, the critical water content was also found in the moist shale adsorption, which means that water has little effect on adsorption when the water content is greater than the critical value (Merkel et al., 2015). However, the experiments and molecular simulation studies suggested that the adsorption amount of methane changes with moisture in a linear correlation (Billemont et al., 2011; Huang et al., 2018b). The effect of water on shale gas adsorption is closely related to the composition, kerogen type, and thermal maturity of shale. Methane and water can be adsorbed on the pore surface of clay minerals and kerogen in different manners. In terms of molecular dynamics, at low moisture content, water molecules would preferentially combine with the oxygen-containing functional groups contained on the surface of kerogen pores. However, as the moisture content increases, water clusters formed in the center of the kerogen pores (Zhao et al., 2017; Huang et al., 2018b). Water molecules are more likely to be adsorbed on the immature kerogen due to more functional groups in immature kerogen (Zhao et al., 2017; Huang et al., 2018b). The water adsorption capacity on the type II kerogen is even higher than that of methane
(Zhao et al., 2018). Although much work has been done on the adsorption of water-bearing shale, methane desorption from water-bearing shale is rarely been reported. Moreover, current studies mainly focus on the influence of a single factor on adsorption, the combined effect of water, temperature, and pressure on the adsorption and desorption of water-bearing shale requires further investigation.

In this study, we have performed the isothermal adsorption and desorption experiments on shale with different water contents at different temperatures. After this, the adsorption and desorption data are fitted by theoretical adsorption and desorption models. Then, the relationship between adsorption capacity, desorption rate and temperature, water content is analyzed. Finally, the ways of temperature, pressure, and water content combinedly affect methane adsorption behavior and desorption hysteresis are further discussed.

\section{Materials and methods}

\subsection{Samples preparation}

A core sample and some shale fragments at the same depth of 2814.0 meters were collected from a well of the PengShui shale gas reservoir located in the southeast of Sichuan, China. The core sample was used to measure the porosity and permeability of the shale matrix. The fragments are used to test the specific surface area (SSA), pore volume $(\mathrm{PV})$, and adsorption-desorption characteristics by gas sorption method. Initially, the core sample was dried at $110{ }^{\circ} \mathrm{C}$ for 10 $\mathrm{h}$, and then the porosity and the permeability were measured. Helium is employed in porosity and permeability measurement due to its non-adsorbing property (Sakurovs et al., 2009). The porosity of the core sample was measured by the autoporosity instrument (YRD-CPor 200) at $25^{\circ} \mathrm{C}$. Later, the ultralow permeability instrument (YRD-CPerm 200) based on the pressure pulse decay method (Dicker and Smits, 1988) was used to measure the permeability at $25{ }^{\circ} \mathrm{C}$. On the other hand, the fragments were dried at $110^{\circ} \mathrm{C}$ for $10 \mathrm{~h}$, weight about 10 grams of the fragments, and crushed it to 100-200 mesh size. A gram of the shale powder is used to test the TOC content by the TOC analyzer (Elab-TOC) under the instruction of GB/T 19145-2003. This test has been conducted three times, and the average of TOC value is taken as final. Meanwhile, the rest of the shale fragments were crushed to 40-80 mesh for sorption measurements. To removed moisture and other gases, the crushed samples were dried at $110^{\circ} \mathrm{C}$ under an evacuated condition for $10 \mathrm{~h}$. Approximately 1.5 grams of the ground samples were used in the low pressure nitrogen adsorption experiments performed on the Kubo-X1000 instrument at $196{ }^{\circ} \mathrm{C}$ according to the standard of SY/T 6154-1995, and the SSA and PV are obtained. The information on the shale sample is given in Table 1.

To further explore the characteristics of methane adsorption in shale with water content, the water-bearing shale samples were obtained by adding water to the dried samples with a size of 40-80 mesh. The excess water was removed by evacuation until the desired water content of the sample was reached (Joubert et al., 1973). Eventually, the samples with the water 
Table 1. Information on the shale sample.

\begin{tabular}{lllllllll}
\hline $\begin{array}{l}\text { Well } \\
\text { NO. }\end{array}$ & $\begin{array}{l}\text { Depth } \\
\mathrm{m}\end{array}$ & $\begin{array}{l}\text { Diameter } \\
\mathrm{cm}\end{array}$ & $\begin{array}{l}\text { Length } \\
\mathrm{cm}\end{array}$ & $\begin{array}{l}\text { Permeability } \\
10^{-6} \mu \mathrm{m}^{2}\end{array}$ & $\begin{array}{l}\text { Porosity } \\
\%\end{array}$ & $\begin{array}{l}\text { TOC } \\
\%\end{array}$ & $\begin{array}{l}\text { BET SSA } \\
\mathrm{m}^{2} / \mathrm{g}\end{array}$ & $\begin{array}{l}\text { PV } \\
\mathrm{cm}^{3} / \mathrm{g}\end{array}$ \\
\hline Long shale 1 & 2814.0 & 2.51 & 4.53 & 0.59 & 4.13 & 3.66 & 22.07 & 0.015 \\
\hline
\end{tabular}

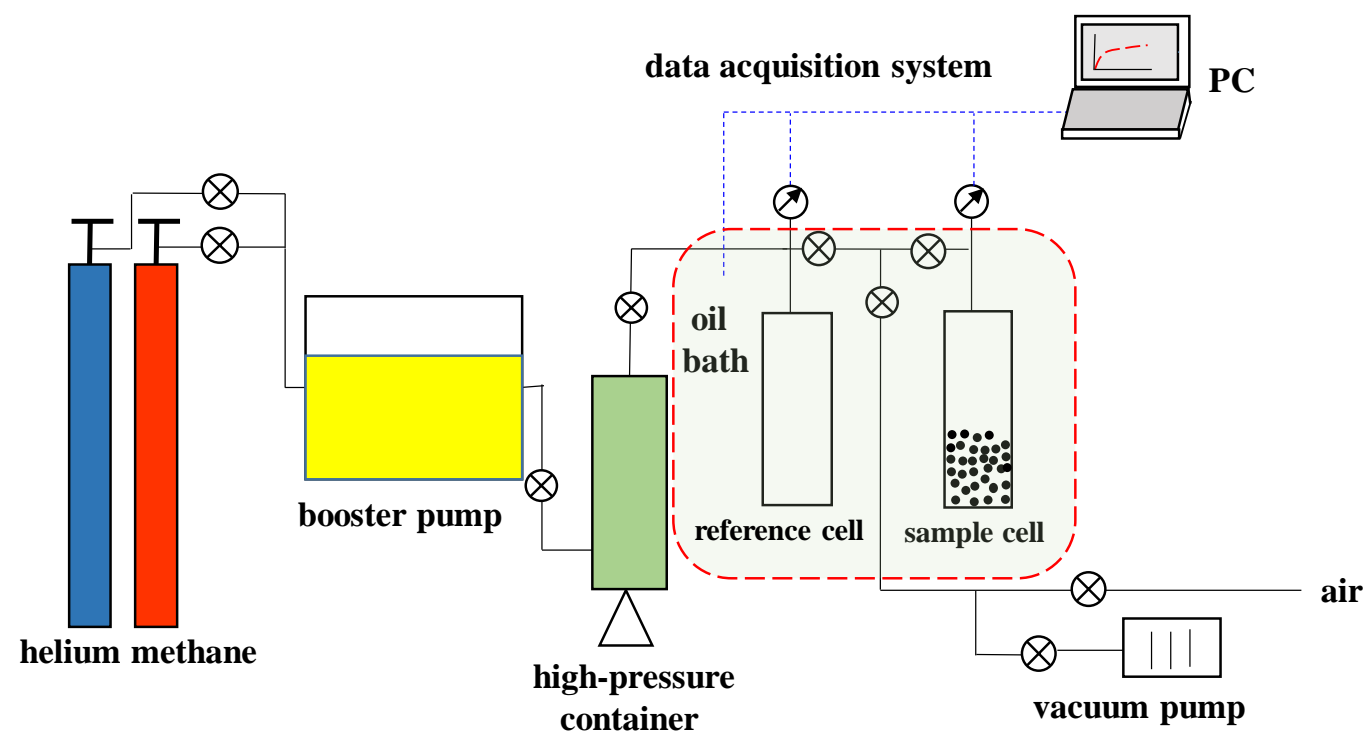

Fig. 1. The schematic diagram of the methane adsorption-desorption apparatus.

content of $0,2 \%, 4 \%$ were obtained. The water content is calculated according to Eq. (1) in this study.

$$
W_{t}=\frac{m_{d r y}-m_{w e t}}{m_{d r y}} \times 100 \%
$$

where $W_{t}$ is the water content (\%); $m_{d r y}$ and $m_{w e t}$ are the mass of shale samples before and after adding water $(\mathrm{g})$.

\subsection{Adsorption and desorption measurement}

The adsorption and desorption of methane in shale with different water contents at different temperatures are measured by the YRD-HPHTsor apparatus according to the standard of GB/T35210.1-2017. The schematic diagram of the adsorptiondesorption apparatus is shown in Fig. 1. The apparatus built on the volumetric method and mainly consists of the gas source, booster pump, gas container, reference cell, sample cell, oil bath, vacuum system, and data acquisition system. The oil bath maintains the temperature changes to within $\pm 0.05{ }^{\circ} \mathrm{C}$ in the entire experimental process. The pressure and temperature of the reference cell and the sample cell were respectively recorded in real-time by pressure transducers and temperature transducers. The main steps of the adsorptiondesorption measurement are as follows:

1) Leakage test: The entire system is pressurized to $28 \mathrm{MPa}$ by helium to check the leakage. The system can ensure accurate measurement if there is no pressure drop for 5 $\mathrm{h}$ at the designed experimental temperature.
2) Reference cell calibration: A known size of the steel block is placed in the sample cell, and helium is introduced from the reference cell to the sample cell. The pressure and temperature of two cells before and after helium expansion is then recorded. After this, change to different sizes of steel blocks and repeat this step. With this, the volume of the reference cell and the connected pipes can be accurately calculated based on the mass balance. The details of the calculation have been published previously (Lu et al., 1995).

3) Void volume determination: Shale samples were placed into the sample cell carefully and quickly. Afterward, the void volume of the sample cell excluding the skeleton of the shale sample can be determined by helium expansions from the known volume of the reference cell to the sample cell.

4) Isothermal adsorption-desorption measurement: The system is evacuated, and the methane is charged into the reference cell. Then, the methane is allowed to expand stepwise from the reference cell to the sample cell until the pressure reaches to the highest designed experimental pressure. The desorption is conducted by methane expansion from the sample cell to the reference cell step by step until the pressure is decreased to $0.5 \mathrm{MPa}$. To ensure that adsorption and desorption reach equilibrium in each pressure step, the time for equilibrium is set to $10 \mathrm{~h}$ in this study. The more detailed description of the experimental procedure has been presented in previous literature (Krooss et al., 2002; Gasparik et al., 2012, 
2014a, 2014b).

The excess adsorption capacity is calculated according to the mass balance shown in Eq. (2).

$$
n_{e x}=\frac{\left(m_{t}-\rho_{g} V_{\text {void }}\right) V_{m}}{m \cdot M_{C H_{4}}}
$$

where $n_{e x}$ is the excess adsorption capacity of methane $\left(\mathrm{cm}^{3} / \mathrm{g}\right.$, STP); $m_{t}$ is the total mass of methane transferred to the sample cell $(\mathrm{g}) ; \rho_{g}$ is the density of bulk methane $\left(\mathrm{g} / \mathrm{cm}^{3}\right) ; V_{\text {void }}$ is the void volume of the sample cell excluding the skeleton of the shale sample $\left(\mathrm{cm}^{3}\right) ; m$ is the mass of shale sample $(\mathrm{g}) ; M_{C H_{4}}$ is the molar mass of methane, which is $16.04 \mathrm{~g} / \mathrm{mol} ; V_{m}$ is the volume occupied by a mole of methane at $101.325 \mathrm{KPa}$, $273.15 \mathrm{~K}$, which is $22,400 \mathrm{~cm}^{3} / \mathrm{mol}$.

\subsection{Adsorption and desorption model}

The Langmuir model is generally considered to be able to characterize the adsorption behavior of most shale (Weniger et al., 2010; Gasparik et al., 2012; Guo, 2013; Wang et al., 2013, 2020). As shown in Eq. (3), however, the parameter of adsorption capacity in the Langmuir model represents the absolute adsorption capacity, and the experimental result is that the excess adsorption ignores the volume occupied by the adsorption phase (Battistutta et al., 2010). The relationship between the absolute adsorption and the excess adsorption is presented in Eq. (4). In this work, to employ the Langmuir model to describe the adsorption behavior of shale gas, the experimentally measured excess adsorption capacity is converted to absolute adsorption capacity according to Eq. (4). It is found from this study that all isotherms have hysteresis, which will be discussed in detail in section 3.1. Considering that the desorption curves are above the adsorption curves, this means that there is a residual adsorption amount at each pressure in the desorption process. However, the shape of the desorption curves are consistent with the Langmuir type sorption, so the $\lambda$ related to hysteresis is added to the Langmuir model, as shown in Eq. (5). It is the Langmuir $+\lambda$ model that has achieved good results in describing the hysteresis of coal-bed methane desorption (Ma et al., 2011). The physical meaning of $\lambda$ in this model is the average residual adsorption (Ma et al., 2011). The adsorption and desorption data are respectively fitted by Eqs. (3) and (5), and the determination coefficient of $R^{2}$ is taken to evaluate the accuracy of the fitting.

$$
\begin{gathered}
n_{a b}=\frac{n_{0} P}{P+P_{L}} \\
n_{a b}=\frac{n_{e x}}{\left(1-\rho_{g} / \rho_{a}\right)} \\
n_{a b}=\frac{n_{0} P}{P+P_{L}}+\lambda
\end{gathered}
$$

where $n_{0}$ is the Langmuir volume $\left(\mathrm{cm}^{3} / \mathrm{g}\right.$, STP), which represents the maximum adsorption capacity; $n_{a b}$ is the absolute adsorption capacity $\left(\mathrm{cm}^{3} / \mathrm{g}, \mathrm{STP}\right) ; \rho_{a}$ is the density of the methane in the adsorbed state $\left(\mathrm{g} / \mathrm{cm}^{3}\right) ; P$ and $P_{L}$ are the experimental pressure and Langmuir pressure, respectively

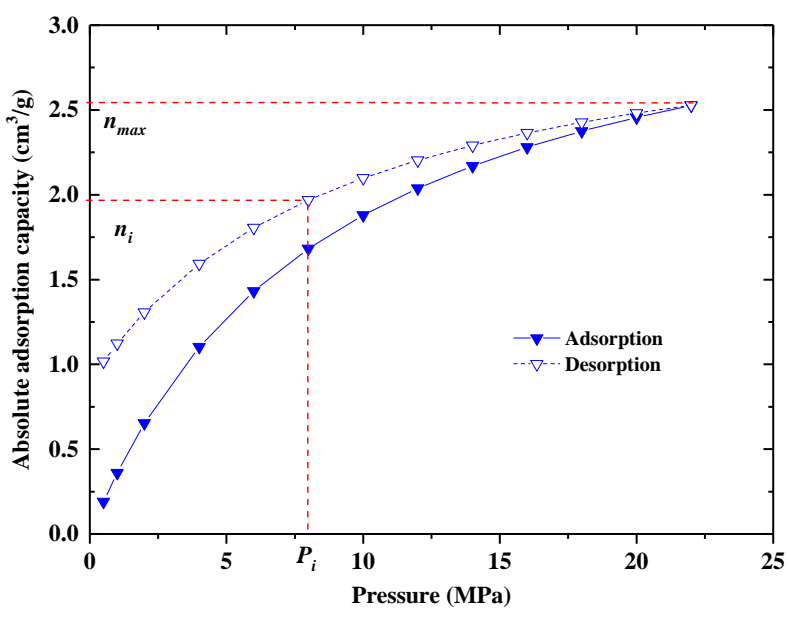

Fig. 2. The illustration of the desorption rate calculation in an isotherm.

(MPa); $\lambda$ is the term related to desorption hysteresis $\left(\mathrm{cm}^{3} / \mathrm{g}\right.$, STP). It is worth noting that the density of the adsorbed methane is required in the absolute adsorption calculation. The values of $\rho_{a}$ have been estimated with different models (Fitzgerald et al., 2003; Li et al., 2015; Wang and Yu, 2016). The commonly used Van der Waals density value of 0.421 $\mathrm{g} / \mathrm{cm}^{3}$ is used in this study (Yuan et al., 2014; Wang and Yu, 2016).

To quantitatively study the desorption capability of methane in water-bearing shale, the parameter of desorption rate $\left(R_{d e}\right)$ is defined here. The desorption rate is the ratio of the accumulated desorbed gas amount to the total adsorbed gas amount when the pressure decreased to a specific value in the desorption process. Fig. 2 illustrates the calculation of the $R_{d e}$, and the desorption rate at the pressure of $P_{i}$ is calculated by Eq. (6).

$$
R_{d e}=\frac{n_{\max }-n_{i}}{n_{\max }} \times 100 \%
$$

where $R_{d e}$ is the desorption rate (\%); $n_{\max }$ is the adsorption amount at the last experimental pressure in the adsorption process $\left(\mathrm{cm}^{3} / \mathrm{g}\right) ; n_{i}$ is the adsorption amount at $P_{i}$ in the desorption process $\left(\mathrm{cm}^{3} / \mathrm{g}\right)$.

\section{Results and discussions}

\subsection{Isothermal adsorption and desorption}

Isothermal adsorption-desorption experiments were performed at $45{ }^{\circ} \mathrm{C}, 60{ }^{\circ} \mathrm{C}$ and $80{ }^{\circ} \mathrm{C}$. The adsorption and desorption data are given in the attachment and are respectively fitted by the Langmuir model and Langmuir $+\lambda$ model. The fitting results are shown in Table 2 and Fig. 3.

A general trend can be found from Fig. 3 that the absolute adsorption capacity increases rapidly with increasing pressure and then it tends to stabilize, which is in line with the type I sorption categorized by IUPAC (Thommes et al., 2015). The desorption hysteresis in coals has been reported in previous literature (Battistutta et al., 2010; Busch and Gensterblum, 2011; Dutta et al., 2011; Kim et al., 2011; Wang et al., 2014a; 
Table 2. Fitting results of methane adsorption and desorption in water-bearing shale.

\begin{tabular}{lllllllll}
\hline \multirow{2}{*}{ Temperature $\left({ }^{\circ} \mathrm{C}\right)$} & \multirow{3}{*}{ Water content $(\%)$} & \multicolumn{3}{c}{ Adsorption-Langmuir } & \multicolumn{4}{c}{ Desorption-Langmuir+ $\lambda$} \\
\cline { 3 - 8 } & & $n_{0}\left(\mathrm{~cm}^{3} / \mathrm{g}\right)$ & $P_{L}(\mathrm{MPa})$ & $\mathrm{R}^{2}$ & $n_{0}\left(\mathrm{~cm}^{3} / \mathrm{g}\right)$ & $P_{L}(\mathrm{MPa})$ & $\lambda\left(\mathrm{cm}^{3} / \mathrm{g}\right)$ & $\mathrm{R}^{2}$ \\
\hline 45 & 0 & 4.636 & 5.375 & 0.9952 & 3.624 & 4.660 & 0.700 & 0.9913 \\
& 2.03 & 4.141 & 6.130 & 0.9991 & 2.597 & 5.605 & 1.201 & 0.9984 \\
& 4.22 & 3.709 & 7.207 & 0.9993 & 2.364 & 7.011 & 1.023 & 0.9989 \\
\hline 60 & 0 & 4.177 & 5.849 & 0.9906 & 3.400 & 5.300 & 0.558 & 0.9758 \\
& 2.05 & 3.913 & 7.396 & 0.9992 & 2.533 & 7.456 & 1.059 & 0.9973 \\
& 4.20 & 3.541 & 8.841 & 0.9989 & 2.325 & 9.399 & 0.900 & 0.9985 \\
\hline 80 & 0 & 3.831 & 6.761 & 0.9902 & 3.198 & 6.936 & 0.591 & 0.9849 \\
& 2.02 & 3.645 & 8.355 & 0.9992 & 2.659 & 10.52 & 0.887 & 0.9991 \\
& 4.25 & 3.425 & 11.270 & 0.9992 & 1.949 & 11.80 & 0.977 & 0.9988 \\
\hline
\end{tabular}

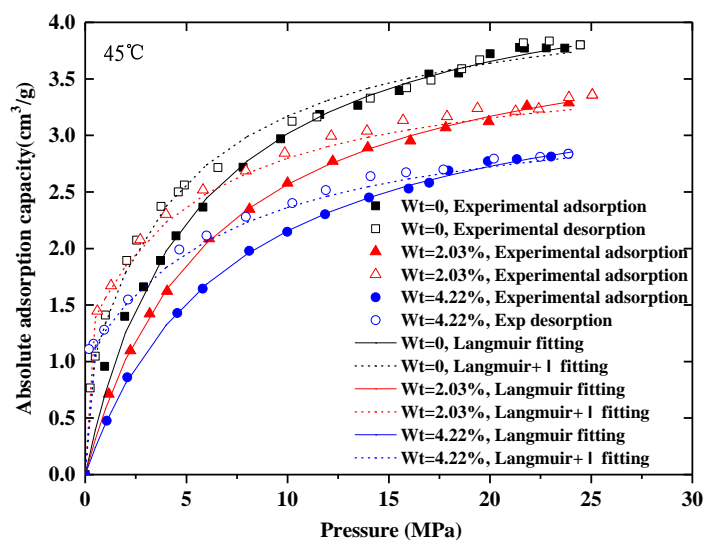

(a)

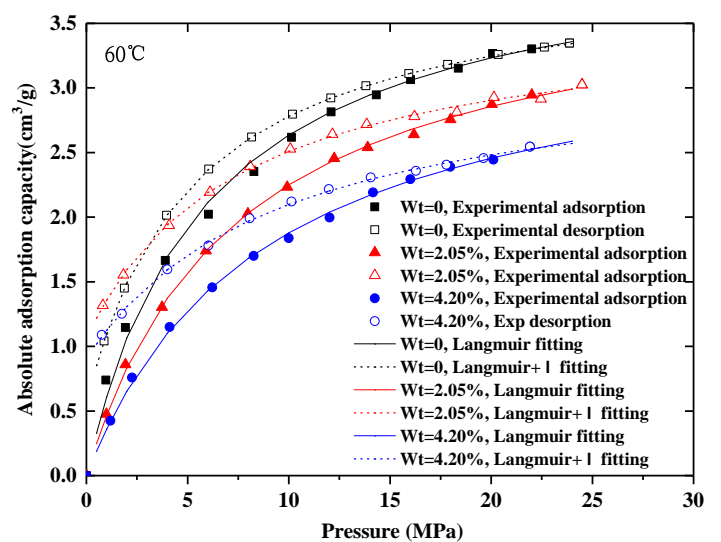

(b)

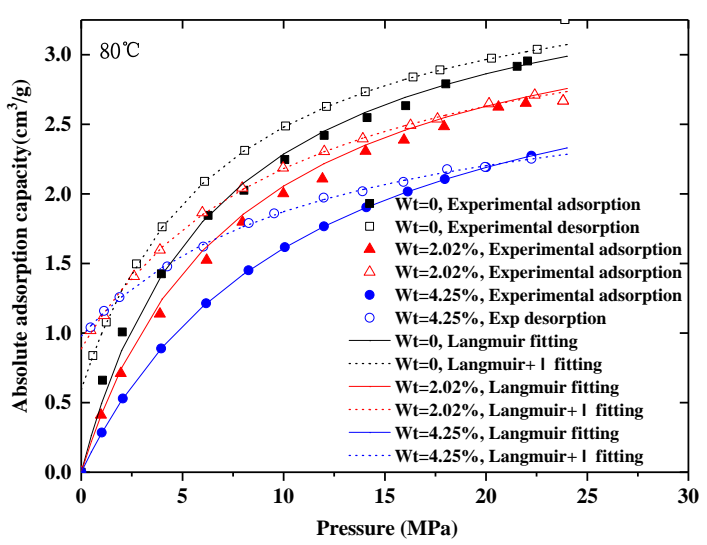

(c)

Fig. 3. Adsorption and desorption of methane in water-bearing shale at (a) $45^{\circ} \mathrm{C}$, (b) $60{ }^{\circ} \mathrm{C}$, and (c) $80{ }^{\circ} \mathrm{C}$.

Zhang et al., 2014; Zhang and Liu, 2017), whereas it is rarely mentioned on shale. The results from Fig. 3 show that the adsorption capacity decreases as the decreasing in pressure during the desorption process. However, the desorption curves are above the adsorption curves at all temperatures and water contents, indicating that the adsorption-desorption of methane in shale is irreversible. Fig. 3 also depicts that the adsorption capacity and desorption hysteresis are significantly affected by temperature and water content, which will be discussed in detail in the following sections. The fitting results in Table 2 show that the Langmuir model and Langmuir $+\lambda$ model have a high fit quality to the adsorption and desorption data, and all values of $\mathrm{R}^{2}$ are higher than 0.97 , which means that the discussions based on the fitting results in the next sections are reasonable.

\subsection{Effect of temperature}

Based on the Langmuir model fitting, the correlation between Langmuir volume, Langmuir pressure and temperature of the dry sample is exhibited in Figs. 4(a) and 4(b). The figures show that the increasing in temperature results in 


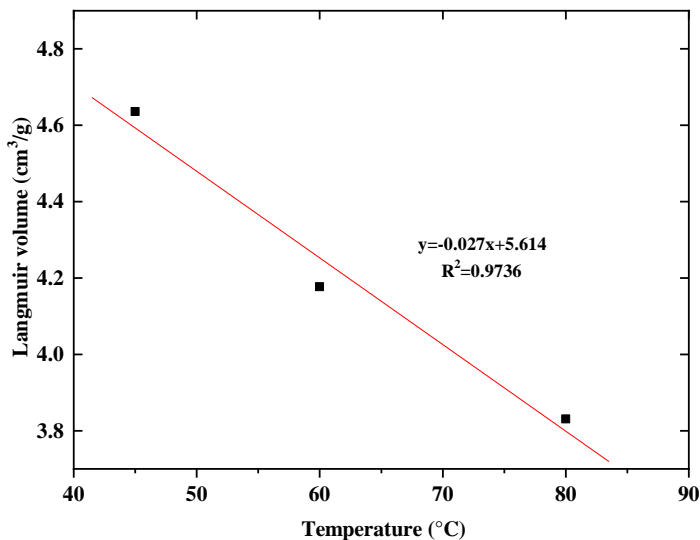

(a)

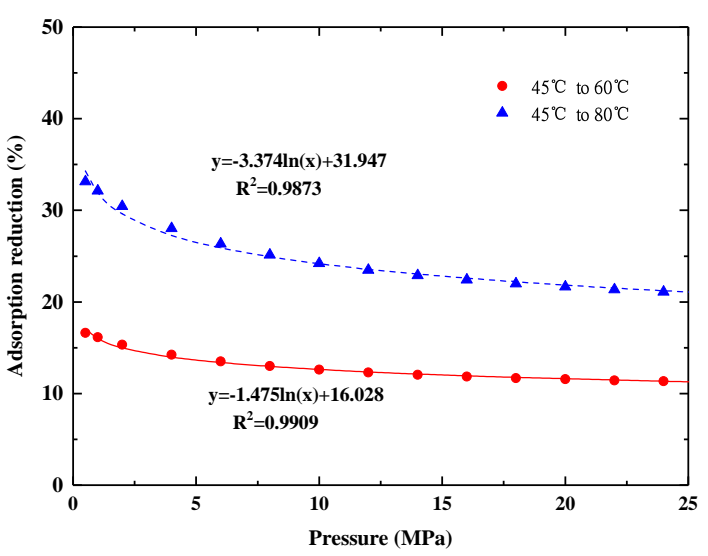

(c)

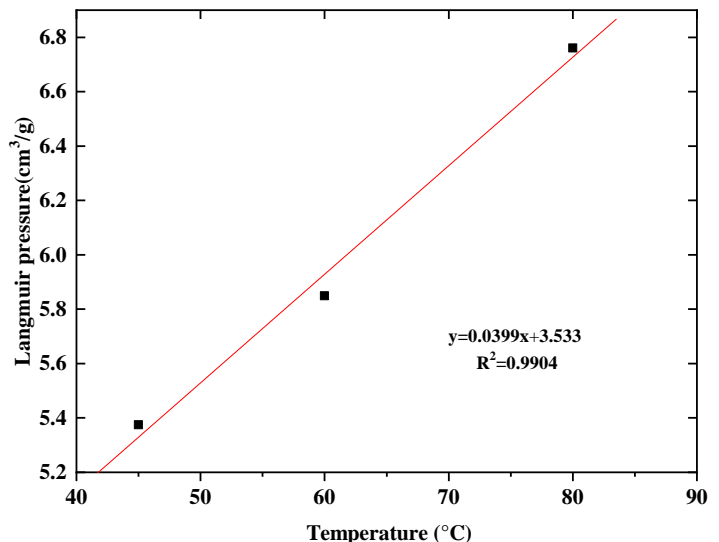

(b)

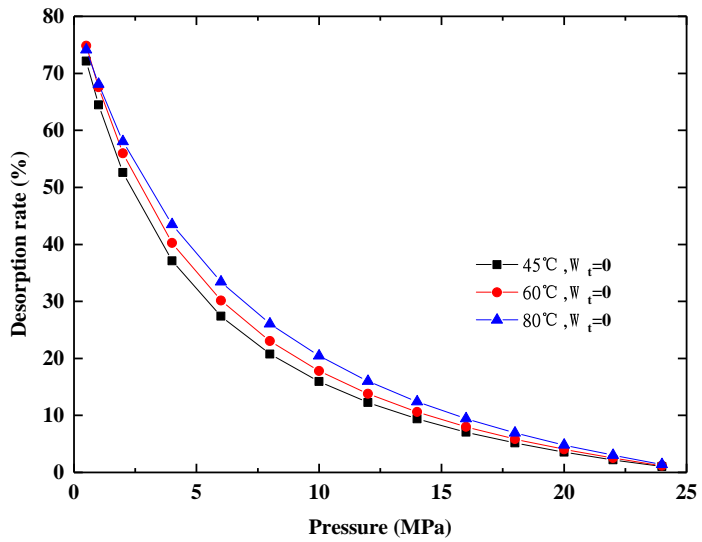

(d)

Fig. 4. Effect of temperature on the (a) Langmuir volume, (b) Langmuir pressure, (c) adsorption reduction, and (d) desorption rate for dry shale sample.

a linearly decrease in Langmuir volume, whereas Langmuir pressure increases linearly. When the temperature increased from 45 to $80{ }^{\circ} \mathrm{C}$, Langmuir volume decreased from 4.636 to $3.831 \mathrm{~cm}^{3} / \mathrm{g}$, and $18 \%$ is reduced. Meanwhile, Langmuir pressure increased from 5.375 to $6.761 \mathrm{MPa}$. Fig. 4(c) shows the effect of temperature on adsorption reduction of dry shale under different pressures. It can be seen that in the experimental pressure range, based on the adsorption at $45{ }^{\circ} \mathrm{C}$, as the temperature increases to $60{ }^{\circ} \mathrm{C}, 11.2 \%$ to $16.6 \%$ of methane adsorption is reduced. However, as the temperature rises to $80{ }^{\circ} \mathrm{C}, 20.9 \%$ to $33.14 \%$ of adsorbed methane is lowered. It may be deduced that the higher the temperature increment, the higher the adsorption reduction. It also can be observed that the adsorption reduction decreases in a logarithmic function as the pressure increases. The adsorption reduction at low pressure is greater than that at high pressure, which means that temperature affects adsorption more evidently at a lower pressure than at high pressure. It might be the methane molecules that have more space for movement under low pressure, as the temperature increases, the absorbed methane molecules tend to desorbed from the shale due to more energy is gained, thus greatly reducing the adsorption capacity. However, under high pressure, the stronger interaction between methane molecules weakens the desorption of the adsorbed gas and reduces the influence of temperature on adsorption reduction. Fig. 4(d) shows the relationship between desorption rate $R_{d e}$ and pressure at different temperatures. It shows that the $R_{d e}$ increases with the decrease of pressure at all temperatures in the desorption process. $R_{d e}$ increases from zero to $75 \%$ when the pressure is decreased from 24 to $1 \mathrm{MPa}$. The higher the temperature, the higher the desorption rate, although the final desorption rates at $1 \mathrm{MPa}$ are almost the same. It is attributed to the exothermic physical nature of adsorption (Zhao et al., 2018). The thermal movement of methane molecules increases with increasing temperature so that the adsorption amount decreases and the desorption rate increases. It can be inferred that increasing the temperature may be the right way to promote the desorption of adsorbed gas in shale reservoirs. Previous numerical simulation studies have shown that fracture heating can improve shale gas recovery effectively (Wang et al., 2014b; Xing et al., 2014; Zhu et al., 2016).

\subsection{Effect of water content}

This section takes the adsorption-desorption results of shale samples with different water contents at $60{ }^{\circ} \mathrm{C}$ as an example to explore the effect of water on shale gas adsorption and desorption. Figs. 5(a) and 5(b) display the 


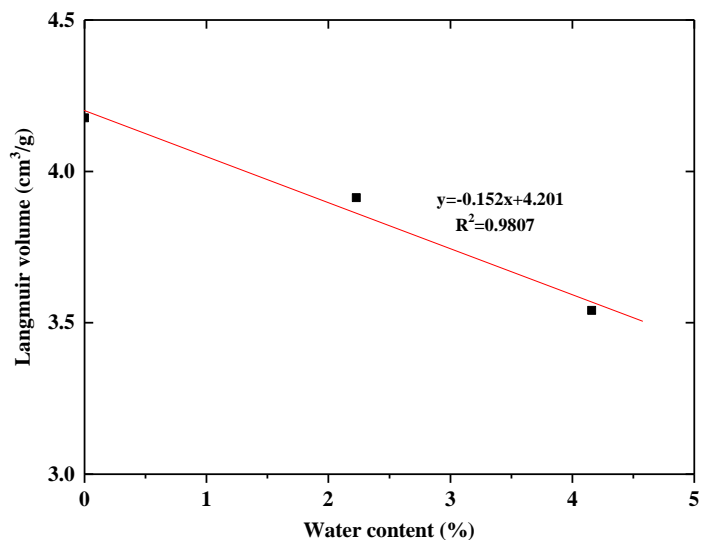

(a)

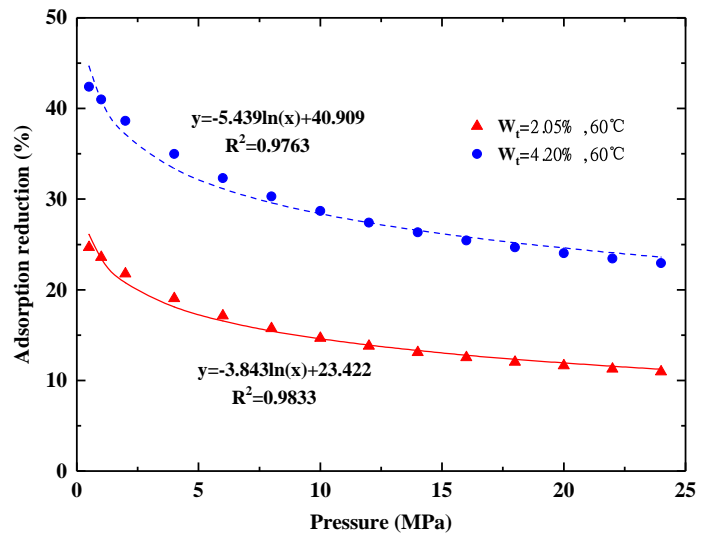

(c)

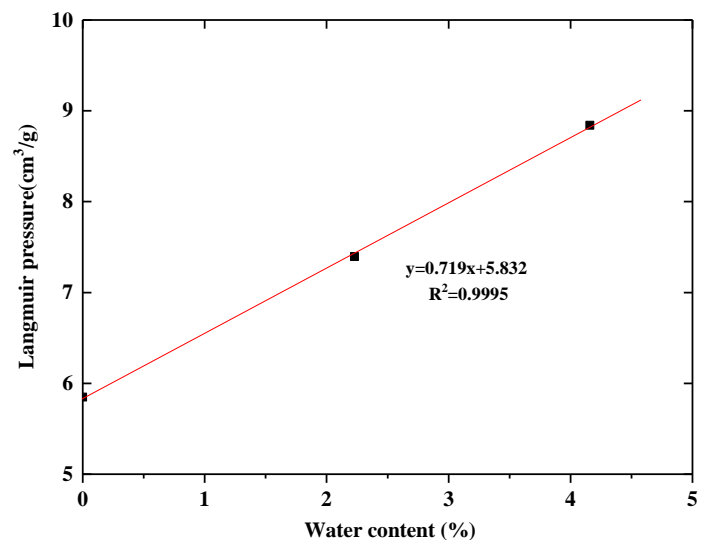

(b)

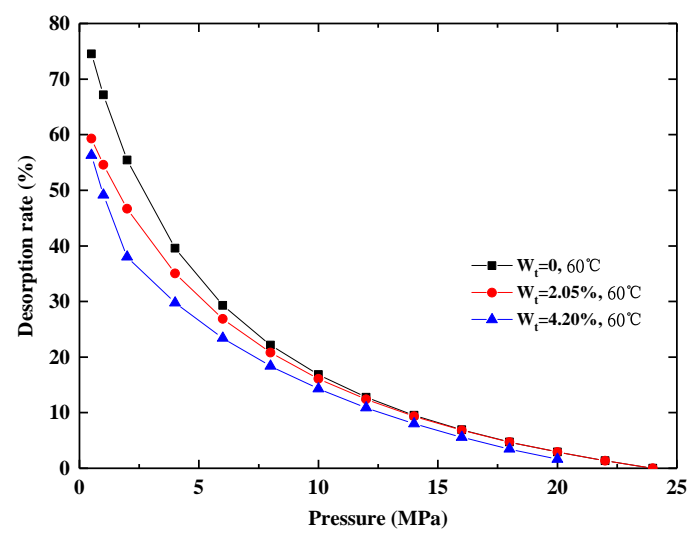

(d)

Fig. 5. Effect of water content on the (a) Langmuir volume, (b) Langmuir pressure, (c) adsorption reduction, and (d) desorption rate for water-bearing shale samples at $60{ }^{\circ} \mathrm{C}$.

relationship between the Langmuir volume, Langmuir pressure and water content. It can be observed that Langmuir volume is negatively correlated with water content, and Langmuir pressure is positively correlated with water content. A $4.2 \%$ increase in water content results in a $15.2 \%$ reduction in Langmuir volume and a $51.2 \%$ increase in Langmuir pressure. It indicates that the presence of water reduces the shale adsorption capacity, and the higher pressure is required for shale to reach the saturated adsorption capacity. It may be because the sites for methane adsorption are mainly distributed on the surface of the pores in organic matter and clay minerals, and water reduces the adsorption sites in organic matter and clay minerals in different ways. Organic matter is usually be considered as hydrocarbon-wet, but a novel investigation found that organic matter is not completely hydrocarbon-wet but mixed-wet, which increases the chance for water entrapment (Hu et al., 2014). It is attributed to the fact that kerogen in the shale reservoir contains hydrophilic oxygen-containing functional groups. Water molecules preferentially combine with the oxygen-containing functional groups when the shale has low water content, so that part of the adsorption sites for methane are occupied by water molecules. When the water content is higher, water in the center of the organic pores in the form of clusters prevents methane molecules from entering the pores, and further decreases the methane adsorption capacity (Huang et al., 2018a). Besides, the clay minerals in shale are hydrophilic. When water comes into contact with the clay minerals, the water film is formed on the clay surface and the active sites for methane adsorption on clay are taken up (Xiong et al., 2017). With the increase of the water content, free water enters the pores of clay minerals. The capillary pressure at the pore throat makes it difficult for gas to enter, leading to a great reduction in methane adsorption.

Fig. 5(c) shows the effect of water content on adsorption reduction at different pressures. It is found that higher water content results in higher adsorption reduction. The adsorption reduction of shale with the water content of $4.2 \%$ is up to $42.4 \%$ in this study, which is lower than the previously reported adsorption reduction of Bossier shale and Haynesville shale (Merkel et al., 2015). The maximum adsorption capacity of Bossier shale and Haynesville shale is respectively decreased by $78 \%$ and $68 \%$ when the samples were moisturized to $97 \%$ RH (Merkel et al., 2015), this may be the properties of the shale we used are very different from the Bossier shale and Haynesville shale. Simulation studies suggested that the effect of water on the adsorption of shale containing immature kerogen is more significant since immature kerogen contains more functional groups (Zhao et al., 2017; Huang 


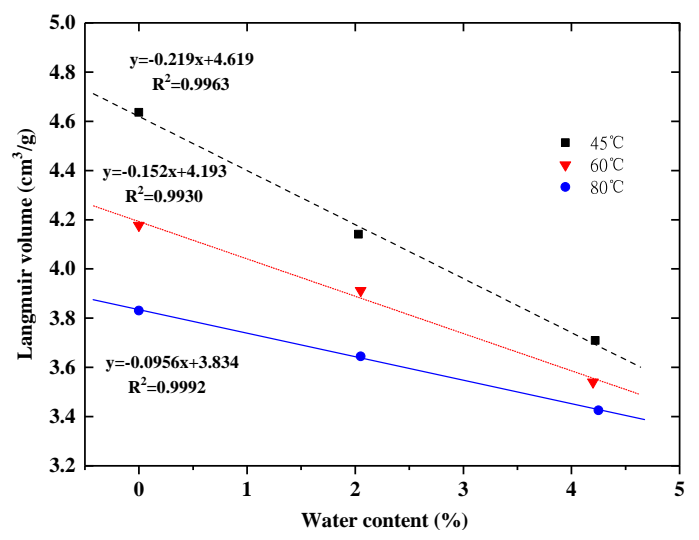

(a)

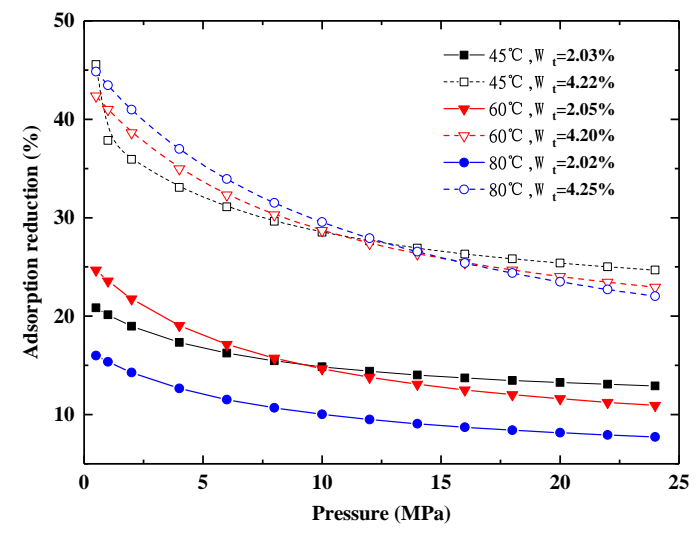

(b)

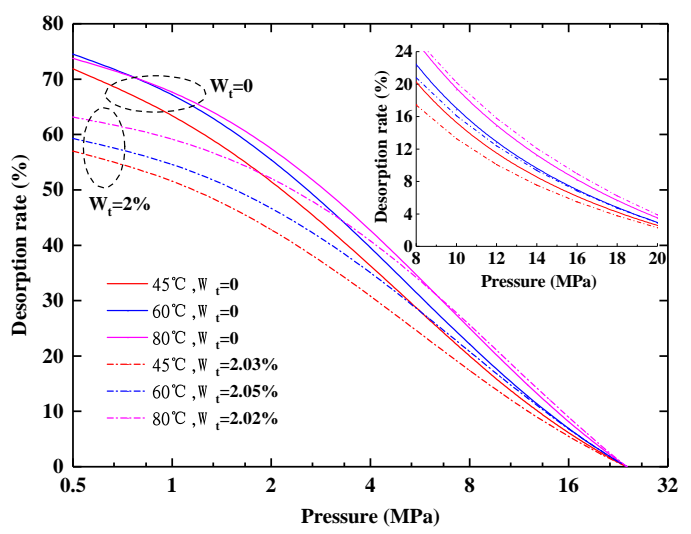

(c)

Fig. 6. Combined effect of temperature, pressure, and water content on the (a) Langmuir volume, (b) adsorption reduction, and (c) desorption rate.

et al., 2018b). However, the adsorption reduction decreases with the increasing in the experimental pressure. When the water content increases from 0 to $2 \%$ and $4 \%$, the adsorption reduction at $2.0 \mathrm{MPa}$ is $21.7 \%$ and $38.6 \%$, while the adsorption reduction at $20 \mathrm{MPa}$ is $11.6 \%$ and $24.0 \%$. It can be speculated that water reduces the gas adsorption capacity at low pressure is more significant than that at high pressure, which is in line with the molecular simulation on methane adsorption in moist kerogen (Zhao et al., 2017). It may be due to the fact that it is difficult for the gas to break through the water block in those water-containing pores at low pressure, and it reduces the chance for gas adsorption on the pore surface. While at high pressure, gas may push the water slugs to move and change the gas-water distribution in the shale pore network. Some pores blocked by water may be reconnected, so the influence of water on gas adsorption becomes weak. The presence of water not only negatively affects the shale adsorption capacity, but also hinders the desorption of shale gas, which makes the desorption hysteresis more serious. As presented in Fig. 5(d), at the same pressure, the shale with higher water content has a lower desorption rate. The reason may be that part of the pores are deformed due to gas adsorption and the presence of water (Battistutta et al., 2010; Zhang et al., 2020), so the adsorbed gas is trapped in such deformed pores, and the desorption only occurs when the pressure drops to a lower level.

\subsection{Combined effect of temperature, pressure, and water content}

From the previous two sections, we realized that the increasing in temperature reduces the Langmuir volume and increases the desorption rate, while the water negatively affects methane adsorption and the desorption. How pressure, temperature, and water combinedly affect methane adsorption behavior and desorption hysteresis are further explored in this section.

Fig. 6(a) presents the relationship between Langmuir volume and water content at different temperatures. It shows that Langmuir volume decreases linearly with the increase of water content at all temperatures, but the slopes of the lines are different. The lower the temperature, the greater the absolute value of the slope, which means that the greater the negative effect of water on Langmuir volume. Compared with dry shale, the results of wet shale with the water content of $4.2 \%$ show that Langmuir volume respectively decreased by $20 \%, 15.2 \%$, and $10.6 \%$ at $45^{\circ} \mathrm{C}, 60{ }^{\circ} \mathrm{C}$, and $80{ }^{\circ} \mathrm{C}$. Besides, the Langmuir volume of shale with low water content is more affected by temperature than shale with high water content. When the temperature increased from 45 to $80^{\circ} \mathrm{C}$, the Langmuir volume of shale samples with the water content of $0,2 \%$, and $4.2 \%$ decreased by $17.9 \%, 12.5 \%$, and $7.7 \%$, respectively. It may 
be suggested that heating to promote desorption in shale gas reservoirs with low water content will be more effective.

Fig. 6(b) shows the relationship between adsorption reduction and external factors of temperature, pressure, and water content. The adsorption reduction decreases with the increasing in pressure as evident in all cases. When the pressure is less than $10 \mathrm{MPa}$, the adsorption reduction drops faster, which means that the temperature and water content has a greater impact on methane adsorption with pressure lower than 10 $\mathrm{MPa}$. In the pressure range of 10 to $24 \mathrm{MPa}$, the adsorption reduction changes slightly. It can be inferred that the adsorption capability is less affected by temperature and water content when the pressure is above $10 \mathrm{MPa}$. In addition, the curves in Fig. 6(b) can be divided into two groups. The upper group represents the adsorption reduction of shale with the water content of $4.2 \%$ at different temperatures, and the lower group represents the adsorption reduction of shale with the content of $2.0 \%$ at different temperatures. It may be concluded that the effect of water on shale gas adsorption is more noteworthy than that of temperature. Molecular simulation studied methane adsorption in water-containing type II kerogen and found that the temperature has a negligible effect on adsorption reduction. While water significantly impacts the methane adsorption in kerogen (Zhao et al., 2017). However, Fig. 6(b) indicates that the effect of temperature on the adsorption reduction cannot be neglected in this study. It differs from the molecular simulation may be because the composition of shale samples we used is more complex than isolated kerogen.

Fig. 6(c) shows the relationship between pressure and the desorption rate of dry shale and wet shale with the water content of $2 \%$ at different temperatures. The results show that when the pressure in the desorption process is lower than 8 $\mathrm{MPa}$, the difference between the desorption rate of the dry sample and the wet sample gradually becomes greater as the pressure decrease, and the dry shale has a higher desorption rate. The inset shows an enlarged view of the desorption rate when the pressure is higher than $8 \mathrm{MPa}$. It can be seen that the higher the temperature, the higher the desorption rate when the pressure is greater than $8 \mathrm{MPa}$. It may be concluded that the effect of water content on the desorption rate is more pronounced when the pressure is lower than $8 \mathrm{MPa}$, and the effect of temperature on the desorption rate is more pronounced when the pressure is higher than $8 \mathrm{MPa}$ during the pressure depletion.

\section{Conclusions}

This work performed the methane adsorption-desorption experiment in shale with different water contents. The Langmuir model and Langmuir $+\lambda$ model are employed to depict the adsorption and desorption hysteresis characteristics of shale gas. Afterward, the relationship between adsorption capacity, desorption rate and temperature, water content is analyzed. Finally, how temperature, pressure, and water content combinedly affect methane adsorption behavior and desorption hysteresis are further discussed. The following conclusions can be drawn:

1) The adsorption and desorption of methane on the water- bearing shale are irreversible. The Langmuir model and Langmuir $+\lambda$ model can characterize the adsorption and desorption hysteresis behavior of shale gas with high accuracy.

2) Increasing temperature reduces the adsorption capacity, but promotes the desorption of shale gas. The adsorption reduction caused by increasing temperature is more evident at a lower pressure than that at high pressure.

3) The role of water in methane adsorption and desorption cannot be ignored. Water negatively affects shale gas adsorption. It might be the water molecules occupy the sites for methane adsorption in organic pores and clay mineral pores. Moreover, the lower the pressure, the more significant will be the effect. Water also hinders the gas desorption from shale. It might be part of the pores that are deformed in the process of methane adsorption in water-bearing shale.

4) The combined effect of temperature, pressure, and water content on shale gas adsorption and desorption should be fully considered. The impact of water on methane adsorption in shale is more significant than the impact of temperature. The lower the temperature, the more obvious the influence of water content on the maximum adsorption capacity of shale gas. As the pressure decreases during the desorption process, the effect of water on desorption is predominant when the pressure is lower than $8 \mathrm{MPa}$, and the effect of temperature on desorption is more pronounced when the pressure is higher than 8 $\mathrm{MPa}$.

\section{Acknowledgement}

This work is funded by the National Natural Science Foundation of China (Nos. 51490654; 51774308), and the National Science and Technology Major Project of China (No. 2016ZX05014-003-002).

\section{Conflict of interest}

The authors declare no competing interest.

Open Access This article is distributed under the terms and conditions of the Creative Commons Attribution (CC BY-NC-ND) license, which permits unrestricted use, distribution, and reproduction in any medium, provided the original work is properly cited.

\section{References}

Ahmad, M., Haghighi, M. Water saturation evaluation of Murteree and Roseneath shale gas reservoirs cooper basin Australia using wire-line logs focused ion beam milling and scanning electron microscopy. Paper SPE 167080 Presented at SPE Unconventional Resources Conference and Exhibition-Asia Pacif, Brisbane, Australia, 11-13 November, 2013.

Al-Mutarreb, A., Jufar, S.R., Abdulelah, H., et al. Influence of water immersion on pore system and methane desorption of shales: A case study of Batu Gajah and Kroh shale formations in Malaysia. Energies 2018, 11(6): 1511-1526.

Battistutta, E., van Hemert, P., Lutynski, M., et al. Swelling 
and sorption experiments on methane, nitrogen and carbon dioxide on dry selar Cornish coal. Int. J. Coal Geol. 2010, 84(1): 39-48.

Billemont, P., Coasne, B., De Weireld, G. An experimental and molecular simulation study of the adsorption of carbon dioxide and methane in nanoporous carbons in the presence of water. Langmuir 2011, 27(3): 1015-1024.

Busch, A., Gensterblum, Y. CBM and $\mathrm{CO}_{2}$-ECBM related sorption processes in coal: A review. Int. J. Coal Geol. 2011, 87(2): 49-71.

Cai, J., Lin, D., Singh, H., et al. A simple permeability model for shale gas and key insights on relative importance of various transport mechanisms. Fuel 2019, 252: 210-219.

Chalmers, G.R.L., Bustin, R.M. On the effects of petrographic composition on coalbed methane sorption. Int. J. Coal Geol. 2007a, 69(4): 288-304.

Chalmers, G.R.L., Bustin, R.M. The organic matter distribution and methane capacity of the lower cretaceous strata of northeastern British Columbia, Canada. Int. J. Coal Geol. 2007b, 70(1-3): 223-239.

Dicker, A., Smits, R. A practical approach for determining permeability from laboratory pressure-pulse decay measurements. Paper SPE 17578 Presented at SPE International Meeting on Petroleum Engineering, Tianjin, China, 1-4 November, 1988.

Dutta, P., Bhowmik, S., Das, S. Methane and carbon dioxide sorption on a set of coals from India. Int. J. Coal Geol. 2011, 85(3-4): 289-299.

Fan, E., Tang, S., Zhang, C., et al. Methane sorption capacity of organics and clays in high-over matured shale-gas systems. Energy Explor. Exploit. 2014, 32(6): 927-942.

Fan, K., Li, Y., Elsworth, D., et al. Three stages of methane adsorption capacity affected by moisture content. Fuel 2018, 231: 352-360.

Fang, C., Huang, Z., Wang, Q., et al. Cause and significance of the ultra-low water saturation in gas-enriched shale reservoir. Nat. Gas Geosci. 2014, 25(3): 471-476.

Fitzgerald, J.E., Sudibandriyo, M., Pan, Z., et al. Modeling the adsorption of pure gases on coals with the SLD model. Carbon 2003, 41(12): 2203-2216.

Gasparik, M., Bertier, P., Gensterblum, Y., et al. Geological controls on the methane storage capacity in organic-rich shales. Int. J. Coal Geol. 2014a, 123: 34-51.

Gasparik, M., Ghanizadeh, A., Bertier, P., et al. High-pressure methane sorption isotherms of black shales from the Netherlands. Energy Fuels 2012, 26(8): 4995-5004.

Gasparik, M., Rexer, T.F.T., Aplin, A.C., et al. First international inter-laboratory comparison of high-pressure $\mathrm{CH}_{4}, \mathrm{CO}_{2}$ and $\mathrm{C}_{2} \mathrm{H}_{6}$ sorption isotherms on carbonaceous shales. Int. J. Coal Geol. 2014b, 132: 131-146.

Ghanbari, E., Dehghanpour, H. The fate of fracturing water: A field and simulation study. Fuel 2016, 163: 282-294.

Guo, S. Experimental study on isothermal adsorption of methane gas on three shale samples from upper Paleozoic strata of the Ordos basin. J. Pet. Sci. Eng. 2013, 110: 132-138.

Herrle, J.O., Pross, J., Friedrich, O., et al. Forcing mechanisms for mid-cretaceous black shale formation: Evidence from the upper Aptian and lower Albian of the vocontian basin (SE France). Palaeogeogr. Palaeoclimatol. Palaeoecol. 2003, 190: 399-426.

Hill, D.G., Nelson, C.R. Gas productive fractured shales: An overview and update. Gas Tips 2000, 6(3): 4-13.

Hu, Y., Devegowda, D., Striolo, A., et al. Microscopic dynamics of water and hydrocarbon in shale-kerogen pores of potentially mixed-wettability. SPE J. 2014, 20(1): 112-124.

Huang, L., Ning, Z., Wang, Q., et al. Effect of organic type and moisture on $\mathrm{CO}_{2} / \mathrm{CH}_{4}$ competitive adsorption in kerogen with implications for $\mathrm{CO}_{2}$ sequestration and enhanced CH4 recovery. Appl. Energy 2018a, 210: 28-43.

Huang, L., Ning, Z., Wang, Q., et al. Molecular simulation of adsorption behaviors of methane, carbon dioxide and their mixtures on kerogen: Effect of kerogen maturity and moisture content. Fuel 2018b, 211: 159-172.

Jarvie, D.M., Hill, R.J., Ruble, T.E., et al. Unconventional shale-gas systems: The mississippian Barnett shale of north-central Texas as one model for thermogenic shalegas assessment. AAPG Bull. 2007, 91(4): 475-499.

Jiao, B., Ding, W., Gu, Y., et al. The reservoir characteristics of marine shale and its effect on the adsorption of methane in northern Guizhou. Pet. Sci. Technol. 2019, 37(21): 2199-2206.

Joubert, J.I., Grein, C.T., Bienstock, D. Sorption of methane in moist coal. Fuel 1973, 52(3): 181-185.

Kim, H.J., Shi, Y., He, J., et al. Adsorption characteristics of $\mathrm{CO}_{2}$ and $\mathrm{CH}_{4}$ on dry and wet coal from subcritical to supercritical conditions. Chem. Eng. J. 2011, 171(1): 45-53.

Krooss, B.M., van Bergen, F., Gensterblum, Y., et al. Highpressure methane and carbon dioxide adsorption on dry and moisture-equilibrated Pennsylvanian coals. Int. J. Coal Geol. 2002, 51(2): 69-92.

Li, J., Li, X., Wang, X., et al. Water distribution characteristic and effect on methane adsorption capacity in shale clay. Int. J. Coal Geol. 2016, 159: 135-154.

Li, Y., Li, X., Wang, Y., et al. Effects of composition and pore structure on the reservoir gas capacity of carboniferous shale from Qaidam basin, China. Mar. Pet. Geol. 2015, 62: 44-57.

Liu, H., Wang, H. Ultra-low water saturation characteristics and the identification of over-pressured play fairways of marine shales in south China. Nat. Gas Ind. 2013, 33(7): 140-144.

Lu, X., Li, F., Watson, A.T. Adsorption measurements in Devonian shales. Fuel 1995, 74(4): 599-603.

Ma, D., Zhang, S., Lin, Y. Isothermal adsorption and desorption experiment of coal and experimental results accuracy fitting. Journal of China Coal Society 2011, 36(3): 477-480. (in Chinese)

Mcglade, C., Speirs, J., Sorrell, S. Unconventional gas-a review of regional and global resource estimates. Energy 2013, 55: 571-584.

Merkel, A., Fink, R., Littke, R. The role of pre-adsorbed water on methane sorption capacity of Bossier and Haynesville shales. Int. J. Coal Geol. 2015, 147-148: 1-8. 
Rexer, T.F., Mathia, E.J., Aplin, A.C., et al. High-pressure methane adsorption and characterization of pores in Posidonia shales and isolated kerogens. Energy Fuels 2014, 28(5): 2886-2901.

Ross, D.J.K., Bustin, R.M. Shale gas potential of the lower Jurassic Gordondale member, northeastern British Columbia, Canada. Bull. Can. Pet. Geol. 2007, 55(1): 51-75.

Sakurovs, R., Day, S., Weir, S. Causes and consequences of errors in determining sorption capacity of coals for carbon dioxide at high pressure. Int. J. Coal Geol. 2009, 77(1-2): 16-22.

Sandoval, D.R., Yan, W., Michelsen, M.L., et al. Modeling of shale gas adsorption and its influence on phase equilibrium. Ind. Eng. Chem. Res. 2017, 57(17): 57365747.

Tan, J., Weniger, P., Krooss, B., et al. Shale gas potential of the major marine shale formations in the upper Yangtze platform, south China, part II: Methane sorption capacity. Fuel 2014, 129: 204-218.

Thommes, M., Kaneko, K., Neimark, A.V., et al. Physisorption of gases, with special reference to the evaluation of surface area and pore size distribution (IUPAC technical report). Pure Appl. Chem. 2015, 87(9-10): 1051-1069.

Wang, G., Ren, T., Wang, K., et al. Influence of maximum pressure on the path of $\mathrm{CO}_{2}$ desorption isotherm on coal. Energy Fuels 2014a, 28(11): 7093-7096.

Wang, H., Ajao, O., Economides, M.J. Conceptual study of thermal stimulation in shale gas formations. J. Nat. Gas Sci. Eng. 2014b, 21: 874-885.

Wang, L., Liu, M., Altazhanov, A., et al. Data driven machine learning models for shale gas adsorption estimation. Paper SPE 200621 Presented at SPE Europe featured at 82nd EAGE Conference and Exhibition, Amsterdam, Netherlands, 8-11 December, 2020.

Wang, L., Yu, Q. The effect of moisture on the methane adsorption capacity of shales: A study case in the eastern Qaidam basin in China. J. Hydrol. 2016, 542: 487-505.

Wang, S., Feng, Q., Javadpour, F., et al. Oil adsorption in shale nanopores and its effect on recoverable oil-in-place. Int. J. Coal Geol. 2015, 147-148: 9-24.

Wang, S., Javadpour, F., Feng, Q. Fast mass transport of oil and supercritical carbon dioxide through organic nanopores in shale. Fuel 2016, 181: 741-758.

Wang, S., Song, Z., Cao, T., et al. The methane sorption capacity of Paleozoic shales from the Sichuan basin, China. Mar. Pet. Geol. 2013, 44: 112-119.

Wattenbarger, R.A., Alkouh, A.B. New advances in shale reservoir analysis using flowback data. Paper SPE 165721 Presented at SPE Eastern Reginal Meeting, Pittsburgh, Pennsylvania, USA, 20-22 August, 2013.

Weniger, P., Kalkreuth, W., Busch, A., et al. High-pressure methane and carbon dioxide sorption on coal and shale samples from the Paraná basin, Brazil. Int. J. Coal Geol. 2010, 84(3-4): 190-205.

Xing, Y., Wang, Y., Wang, D. Numerical simulation of enhancing desorption of shale gas by electrical heating. Xi' an Shiyou University (Natural Science Edition) 2014, 29(6): 74-78. (in Chinese)

Xiong, J., Liu, X., Liang, L., et al. Investigation of methane adsorption on chlorite by grand Canonical Monte Carlo simulations. Pet. Sci. 2017, 14(1): 37-49.

Yang, F., Xie, C., Ning, Z., et al. High-pressure methane sorption on dry and moisture-equilibrated shales. Energy Fuels 2017, 31(1): 482-492.

Yang, R., Jia, A., Hu, Q., et al. Particle size effect on water vapor sorption measurement of organic shale: One example from Dongyuemiao member of lower Jurassic Ziliujing formation in Jiannan area of China. Adv. GeoEnergy Res. 2020, 4(2): 207-218.

Yuan, W., Pan, Z., Li, X., et al. Experimental study and modeling of methane adsorption and diffusion in shale. Fuel 2014, 117: 509-519.

Zeng, F., Zhang, Q., Guo, J., et al. Capillary imbibition of confined water in nanopores. Capillarity 2020, 3(1): 8-15.

Zhang, J., Tang, Y., Chen, D. Prediction of methane adsorption content in continental coal-bearing shale reservoir using SLD model. Pet. Sci. Technol. 2019, 37(15): 1839-1845.

Zhang, K., Cheng, Y., Wang, L., et al. Pore morphology characterization and its effect on methane desorption in water-containing coal: An exploratory study on the mechanism of gas migration in water-injected coal seam. J. Nat. Gas Sci. Eng. 2020, 75: 103152.

Zhang, L., Aziz, N., Ren, T., et al. Influence of coal particle size on coal adsorption and desorption characteristics. Arch. Min. Sci. 2014, 59(3): 807-820.

Zhang, R., Liu, S. Experimental and theoretical characterization of methane and $\mathrm{CO}_{2}$ sorption hysteresis in coals based on Langmuir desorption. Int. J. Coal Geol. 2017, 171: 49-60.

Zhang, T., Ellis, G.S., Ruppel, S.C., et al. Effect of organicmatter type and thermal maturity on methane adsorption in shale-gas systems. Org. Geochem. 2012, 47: 120-131.

Zhao, T., Li, X., Ning, Z., et al. Molecular simulation of methane adsorption on type II kerogen with the impact of water content. J. Pet. Sci. Eng. 2018, 161: 302-310.

Zhao, T., Li, X., Zhao, H., et al. Molecular simulation of adsorption and thermodynamic properties on type II kerogen: Influence of maturity and moisture content. Fuel 2017, 190: 198-207.

Zhu, G., Yao, J., Sun, H., et al. The numerical simulation of thermal recovery based on hydraulic fracture heating technology in shale gas reservoir. J. Nat. Gas Sci. Eng. 2016, 28: 305-316. 